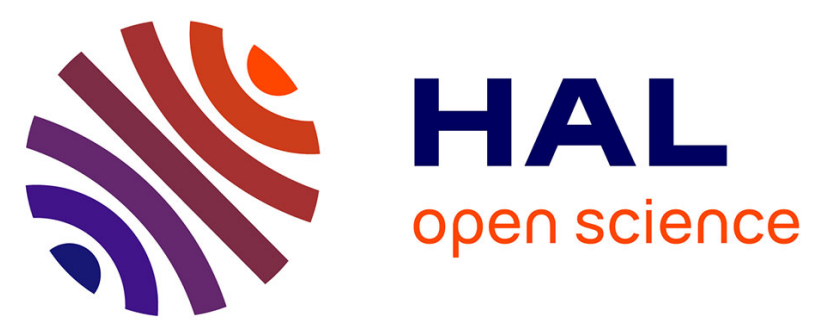

\title{
Intraspecific signals inducing aggregation in Periplaneta americana (L.) (Insecta: Dictyoptera)
}

\author{
Imen Saï, Christian Malosse, Virginie Durier, Colette Rivault
}

\section{To cite this version:}

Imen Saïd, Christian Malosse, Virginie Durier, Colette Rivault. Intraspecific signals inducing aggregation in Periplaneta americana (L.) (Insecta: Dictyoptera). Environmental Entomology, 2015, 44 (3), pp.713-723. 10.1093/ee/nvv035 . hal-01305661

\section{HAL Id: hal-01305661 \\ https://hal.science/hal-01305661}

Submitted on 21 Jul 2016

HAL is a multi-disciplinary open access archive for the deposit and dissemination of scientific research documents, whether they are published or not. The documents may come from teaching and research institutions in France or abroad, or from public or private research centers.
L'archive ouverte pluridisciplinaire HAL, est destinée au dépôt et à la diffusion de documents scientifiques de niveau recherche, publiés ou non, émanant des établissements d'enseignement et de recherche français ou étrangers, des laboratoires publics ou privés. 


\section{INTRASPECIFIC SIGNALS INDUCING AGGREGATION IN PERIPLANETA AMERICANA (L.) (INSECTA: DICTYOPTERA)}

Imen Saïd ${ }^{1}$, Christian Malosse ${ }^{2}$, Virginie Durier ${ }^{3}$, Colette Rivault ${ }^{3}$

\section{Said $(\square)$}

${ }^{1}$ Faculté des Sciences de Gafsa, Université de Gafsa, Campus Zarroug, 2112 Gafsa, Tunisia E-mail: imensaid@gmx.fr

\section{Christian}

${ }^{2}$ Unité de Spectrométrie de Masse Structurale et Protéomique, Institut Pasteur, 75015 Paris, France

\section{Virginie, R. Colette}

${ }^{3}$ laboratoire d'éthologie animale et humaine, Université de Rennes I Campus de Beaulieu, 35042 Rennes Cedex, France 


\begin{abstract}
Chemical communication is necessary to induce aggregation and to maintain the cohesion of aggregates in Periplaneta americana (L.) cockroaches. We aimed to identify the chemical message inducing aggregation in this species. Two types of bioassays were used, binary choice tests in Petri dishes and tests in Y-olfactometer. Papers conditioned by direct contact of conspecifics induce aggregation when proposed in binary choice tests and were attractive in a Y-olfactometer. The identification of the molecules present on these conditioned papers indicated that dichloromethane extracts contained mainly cuticular hydrocarbons whereas methanol extracts contained more volatile molecules. Only a mixture of extracts in both solvents induced aggregation. High concentrations of cuticular hydrocarbons are necessary to induce aggregation when presented alone. When presented with volatile molecules present in methanol extracts, low concentrations of cuticular hydrocarbons are sufficient to induce aggregation if they are presented in contact. Among volatile molecules collected on filter paper, a mixture of three compounds: hexadecanoic acid, pentadecanoic acid and pentaethylene glycol induced aggregation. Our results provide evidence that aggregation processes in $P$. americana relies on a dual mechanism: attraction over long distances by three volatile molecules and maintenance on site by contact with cuticular hydrocarbons.
\end{abstract}

Key words: Periplaneta americana, aggregation, cuticular hydrocarbons, volatile fatty acids, behavioural tests. 


\section{Introduction}

Animal aggregation is a general phenomenon that can be seen as a collection of units arranged in space to form a coherent whole (Parrish and Hamner 1997, Krause and Ruxton 2002). Among the many definitions given to the word aggregation, two main types of grouping can be distinguished: - active aggregation when animals are recruited to a particular location by an environmental attractive source (food, shelter...) although they do not interact with one another, and - congregation when the attractive source is the group itself (Parrish and Hamner 1997). Individuals of many species present alternate phases of dispersion and aggregation depending on their current behaviour. After a dispersion phase they are able to form cohesive groups that rely not only on their individual abilities to find the best suitable environmental conditions but also on their abilities to recognize group members and to distinguish them from individuals of other groups of the same species or individuals of another species that they avoid when necessary. Usually aggregates are formed in places presenting particular microclimatic conditions that fulfil the ecological requirements of the species. For example, choice of rest sites can be oriented by microclimatic factors such as temperature, humidity, darkness, size, nature of substrate, etc. Disruption of favourable climatic conditions induces the departure of the animals. Climatic conditions are not the only factors that force animals to form congregations together, social cues orient them towards one another and consequently they gather on a common site. When a group is maintained by mutual attraction of group members (Grassé 1952), it necessitates active information transfer among individuals.

In insects, information is often conveyed by chemical messages or pheromones. Pheromones are molecules secreted to the outside by some individuals and perceived and analysed by conspecifics to orient their behaviour (Wyatt 2003). They can be classified in six functional groups: sex, aggregation, dispersal, alarm, recruitment and maturation. The pheromone message informs conspecifics about the presence of a resource or about their ability to mate. In insects, group formation is often sustained by release of an aggregation pheromone, which induces a behavioural response by conspecifics leading to congregation, i.e. leading to an increase of the density of individuals in the vicinity of the emitting individuals (Ali and Morgan 1990). Contrary to sex pheromones, aggregation pheromones attract conspecifics of either sexes or the same sex as the emitter (Wertheim et al. 2005). Aggregation pheromones have been defined as having an arrestant effect that slows the linear progression by reducing the speed of locomotion or by increasing turning rates and thus inducing the maintenance of 
individuals on a selected area (Ali and Morgan 1990). This definition restricts the pheromone action to a local area when individuals are passing by. To increase encounter probability, attraction from a distance is necessary to improve the effective radius of the aggregation pheromone where, for example, bark beetle larvae follow a pheromone gradient to locate the pheromone source or the emitting conspecifics (Deneubourg et al. 1990). Aggregation processes first necessitate oriented movements towards an attractive source and then individuals are maintained in the selected area by increase in the frequency of contacts among individuals, which permit close range chemical interactions (Applebaum and Heifetz 1999) where they can benefit from aggregation to feed on their host plant and to overcome their host's resistance (Borden 1974, Byers 1989).

Many cockroach species are known to be gregarious (Cornwell 1968) although the mechanisms of group formation are not clearly established. Adult males and females and nymphs of all developmental stages gather together in common shelters during their diurnal resting phase (Roth and Willis 1960, Cornwell 1968, Bell and Adiyodi 1982). During the nocturnal phase, each individual forages in the areas surrounding the shelters where they are able to return using navigation cues and chemical communication (Rivault and Durier 2004). Aggregates are maintained by mutual attraction among members due to chemical communication (Rivault and Cloarec 1998, Rivault et al. 2002). Aggregation pheromones are clearly identified in only a few cockroach species. In Blaberus craniifer (B.), the pheromone produced by the mandibular glands, is a mixture of undecane and tetradecane (Brossut et al. 1974). In Blaberus distanti (K.), it is a mixture of undecane, 4-heptanone, 2,6-dimethyl-4heptanone and octanol (Brossut 1979). In Blattella germanica (L.), the identification of the active molecules remains unclear although data indicate that molecules secreted from the rectal pad cells into the rectum and then excreted with the faeces are able to induce aggregation (Ishii and Kuwahara 1967), other chemical components also induce attraction such as lactic acid (McFarlane and Alli 1986), free fatty acids (Ritter and Persoons 1975) alkylamines and blattellastanoside A and B (Sakuma and Fukami 1990; Sakuma and Fukami 1993), or cuticular hydrocarbons (Rivault et al. 1998).

Among urban cockroach species, Periplaneta americana (L.) is gregarious and chemical communication is clearly involved in aggregation processes. Papers conditioned by conspecific odours are chosen as resting sites (Leoncini and Rivault 2005). Cuticular hydrocarbons play an important part in this message that enables aggregation on the odour source through tactile and/or volatile pathways (Saïd et al. 2005a). Nevertheless, the concentration of cuticular hydrocarbons necessary to induce aggregation on a conditioned site 
must be very high, far beyond biological levels (Saïd et al. 2005a). Therefore, we assumed that cuticular hydrocarbons do not carry the entire aggregation message and that other molecules must be involved. We hypothesized that a volatile part of the message should attract cockroaches over longer distances than cuticular hydrocarbons. After attraction to a specific locality, the increase in frequency of contact among individuals permits close-range chemical interactions via cuticular hydrocarbons. Cuticular hydrocarbons could then act as an arrestant signal capable of maintaining cockroaches around the signal source.

Our aim was to identify emitted volatile secretions of $P$. americana and to evaluate their attractive effects and to investigate their action in aggregation processes in relation to the presence of cuticular hydrocarbons.

\section{Material and methods}

\section{Insect breeding}

P. americana (Insecta: Dictyoptera) were reared in stock colonies at $27^{\circ} \mathrm{C}$ under a $12 \mathrm{~h}$ dark-12 h light photocycle. Commercial dog pellets and water were provided ad libitum.

Two types of behavioural bioassays evaluated the efficiency of the chemical stimuli to attract conspecific cockroaches and to induce aggregation: binary choice tests in Petri dishes and tests in a Y-olfactometer.

\section{Binary Choice Tests}

Tests were made in round plastic Petri dishes (diameter: $140 \mathrm{~mm}$, height $15 \mathrm{~mm}$ ). Tests were put in place during the light phase of a diurnal cycle, during the cockroach resting phase. Groups of 10 first instar nymphs were presented a choice between two filter papers used as resting sites. Papers folded in ' $\mathrm{W}$ ' and placed upright in the dish, measured $9 \mathrm{~cm}^{2}(1.5 \times 6 \mathrm{~cm})$. During tests nymphs were deprived of water and food. Each larva was used only once to avoid bias in results.

One of the filter papers was a control paper and the other one was conditioned with different odours as detailed below.

Data were collected $24 \mathrm{~h}$ later when nymphs had spent an entire circadian cycle in the test dishes and had had the opportunity to choose their rest site. Numbers of individuals on each filter paper were then counted. 
Papers were conditioned either by live insects or by extracts in different solvents of these conditioned papers. For all the tests involving solvent extracts, papers were prepared 15 hours prior to the test to let the solvent evaporate completely.

\section{1- Control tests}

Cockroaches were given the choice between two clean filter papers to verify the symmetry of the experimental set up and the use of filter papers as resting sites by the nymphs.

\section{2- Conspecific contact conditioned papers (CC papers)}

Papers were conditioned by placing them in a dish with normally fed and watered nymphs during the first three days of the first instar with a ratio of 20 nymphs per paper. During this time, nymphs rested on these papers and thus the papers were conditioned by general body contact.

Nymphs were given a choice between a CC paper and a control clean filter paper.

\section{3- CC paper extracts}

CC papers were extracted in two solvents, dichloromethane (SDS, France, purity: 99.95\%) for apolar compounds, and methanol (SDS, France, purity: 99.95\%) for more polar compounds. Papers were immersed first in dichloromethane for $2 \mathrm{~min}$, and then in methanol for $2 \mathrm{~min}$. Extracts were concentrated under nitrogen flow. The solvent was evaporated so that $10 \mu \mathrm{l}$ of the extract corresponded to one filter paper. Extracts were preserved at $-18^{\circ} \mathrm{C}$.

Dichloromethane and methanol extracts of CC papers were tested separately or in mixture. When only one extract was tested, $10 \mu \mathrm{l}$ of that extract were deposited on one paper. Control papers were obtained by depositing $10 \mu \mathrm{l}$ of the corresponding solvent on a paper. When both extracts were presented together, $10 \mu 1$ of each extract were deposited on the same filter paper and $10 \mu$ of each solvent on the control paper.

Nymphs were given a choice between: - a CC paper extract in dichloromethane and a solvent control; - a CC paper extract in methanol and a solvent control; - a mixture of both types of extracts and a control solvent.

\section{4- Conspecific volatile conditioned papers (VC papers)}

Odours emitted by nymphs were trapped with filter paper in an airtight glass vial. Ten last instar nymphs were placed in a tight glass vial connected to a glass cartridge containing adsorbent substrate. Nymphs were replaced every three hours for two successive 12-h photophases. The vial with nymphs was ventilated by a charcoal purified humidified air flow (pump New air, France) carrying odours to the glass cartridge containing filter papers, which are an effective adsorbent of P. americana volatiles (Tirard et al. 2002). 
Nymphs were given a choice between a VC paper and a control clean filter paper.

5 - VC paper extracts

The extraction process used for VC papers was the same as for CC papers. VC papers were extracted only in methanol. Methanol extracts were preferred because methanol gave a better extraction of the more volatile part of the profile present on the CC papers. Ten $\mu$ of the extract corresponded to one filter paper. Ten $\mu l$ of the methanol extracts were deposited on one paper. The control paper was obtained by depositing $10 \mu \mathrm{l}$ of methanol on one paper.

Nymphs were given a choice between a paper with VC paper extracts and a solvent control.

\section{6- Synthetic Fatty acids}

Methanol solutions of seven synthetic chemical compounds (Sigma Aldrich, Germany) identified in the VC paper extracts were prepared at $10 \mu \mathrm{g} / \mu \mathrm{l}$, then serially diluted: dodecanoic acid (purity: 99\%), tetradecanoic acid (purity: 95\%), pentadecanoic acid (purity: 99\%), hexadecanoic acid (purity: 99\%), hexadecenoic acid (purity: 99\%), octadecanoic acid (purity: 99\%) and penthaethylene glycol (purity: 98\%). Ten $\mu \mathrm{l}$ of a $100 \mathrm{ng} / \mu \mathrm{l}$ solution of one chemical compound was deposed on a filter paper (total dose $1 \mu \mathrm{g}$ ).

Nymphs were given a choice between a paper conditioned with one of the compounds and a solvent control paper.

A mixture of two fatty acids (hexadecanoic acid and pentadecanoic acid) and penthaethylene glycol was prepared following their relative proportions in the VC paper methanol extracts: $70 \mu \mathrm{g}$ hexadecanoic acid $+20 \mu \mathrm{g}$ pentadecanoic acid $+10 \mu \mathrm{g}$ penthaethylene glycol.

Nymphs were given a choice between a paper conditioned with this mixture and a solvent control.

\section{Tests in a Y-Olfactometer}

The role of volatile components in the aggregation behaviour of $P$. americana was tested in a Y-olfactometer. Males were tested individually in a glass Y-olfactometer (two 25 $\mathrm{cm}$ long arms and a $20 \mathrm{~cm}$ long common stem, the arms were $3 \mathrm{~cm}$ in diameter). The two arms were connected to the common stem with external Teflon-covered screws so that the connection could not be detected from inside. A pump (New air, France) drew air at a constant flow rate $(150 \mathrm{ml} / \mathrm{min})$ controlled by a flow-meter (Brooks, U.S.A.). The air was humidified and purified with active charcoal before reaching the olfactometer. Each arm was 
connected to one glass vial (50 or $250 \mathrm{ml}$ ), sealed with Teflon screws, containing the odour sources. The air flow through the left arm carried the stimulus and the air flow through the right arm carried the control odour. For each bioassay, males to be tested were isolated, 12 hours before a test, in small plastic boxes, thus avoiding $\mathrm{CO}_{2}$ anaesthesia just before a test. At the beginning of a test, one of these boxes was placed in front of the common stem of the olfactometer to let the tested male in without the experimenter having to manipulate it. The activity of each male was recorded for $5 \mathrm{~min}$. The olfactometer was cleaned after each test.

1- Control tests. Males were given a choice between two odourless air flows to verify the experimental set up.

2- CC papers. These papers were prepared following the method described previously (papers were conditioned for three days with a ratio of 20 first instar nymphs per paper). Males were given a choice between the odour emitted by six CC papers and clean air to test the attraction of volatile components in the odorized arm.

3-CC paper methanol extracts. As methanol extracts carry more volatile components, males were given a choice between an air flow carrying the odour of $60 \mu 1$ of $\mathrm{CC}$ paper methanol extracts deposited on a filter paper and an air-flow carrying the odour of $60 \mu \mathrm{l}$ of methanol deposited on a filter paper.

\section{4- $\mathrm{CH}$ extracts in Dichloromethane}

$\mathrm{CH}$ extracts in dichloromethane were proposed to the tested males to test the effect of more heavy molecules contained in the CC paper blend. Extracts were obtained with previously frozen first instar nymphs that were immersed in dichloromethane for $2 \mathrm{~min}$. After removing the cockroaches, extracts were evaporated under nitrogen flow until a volume corresponding to a concentration of 20 equivalent nymphs / $10 \mu 1$ was reached. An equivalent larva is defined as the amount of CHs extracted from one larva (Heifetz et al. 1997). This concentration was chosen because CC papers were conditioned by 20 first instar nymphs per paper. $\mathrm{CH}$ extracts were preferred to dichloromethane $\mathrm{CC}$ paper extracts to avoid pollution by molecules from faeces although these extracts contained mainly $\mathrm{CHs}$.

Males were given the choice between an air flow carrying the odour of $60 \mu \mathrm{lof} \mathrm{CH}$ extracts deposited on a filter paper and an air-flow carrying the odour of $60 \mu 1$ of dichloromethane deposited on a filter paper.

\section{5- CC paper methanol extracts with $\mathrm{CH}$ extracts presented with contact possibility.}

As $\mathrm{CH}$ extracts might be perceived mainly by contact instead of through the olfactory channel, they were presented on a disc of filter paper placed inside the far end of the arm odorized by $\mathrm{CC}$ paper methanol extracts. We hypothesized that the CC paper methanol 
extracts would attract the males into the odorized arm and the presence of the $\mathrm{CH}$ extracts would arrest them in that arm.

Males were given a choice between an air-flow carrying the odour of $60 \mu 1$ of CC paper methanol extracts deposited on a filter paper and an air-flow carrying the odour of $60 \mu 1$ of methanol deposited on a filter paper. The arm odorized by the CC paper methanol extracts contained a filter paper disc (diameter $=3 \mathrm{~cm}$ ) conditioned with $30 \mu \mathrm{l}$ of $\mathrm{CH}$ extracts (20 equivalent nymphs / $10 \mu \mathrm{l}$ ). This disc was placed at the far end inside this arm to allow direct contact by nymphs.

6- VC papers. VC papers containing volatile odours emitted by nymphs were prepared as described above. Males were given a choice between the odour emitted by six VC papers and clean air.

7- VC paper methanol extracts. VC paper methanol extracts were prepared as described above. Males were given a choice between an air-flow carrying the odour of $60 \mu 1$ of this extract deposited on a filter paper and an air-flow carrying the odour of $60 \mu 1$ of methanol deposited on a filter paper.

\section{Chemical analyses}

\section{Gas chromatography (GC) analyses}

CC and VC paper extracts were analysed by GC. The GC analyses were made with two different column-oven programs (Saïd et al. 2005a).

The first program was adapted to $\mathrm{CHs}$. It started at $100^{\circ} \mathrm{C}$, and then temperature was increased gradually up to $210^{\circ} \mathrm{C}$ at $20^{\circ} \mathrm{C} / \mathrm{min}$, and again up to $320^{\circ} \mathrm{C}$ at $4^{\circ} \mathrm{C} / \mathrm{min}$. The final temperature hold time was $15 \mathrm{~min}$.

The second program was adapted to volatile molecules. It started at $35^{\circ} \mathrm{C}$ for $1 \mathrm{~min}$, then temperature increased gradually up to $50^{\circ} \mathrm{C}$ at $20^{\circ} \mathrm{C} / \mathrm{min}$ and stayed at $50^{\circ} \mathrm{C}$ for $5 \mathrm{~min}$, then temperature increased to $250^{\circ} \mathrm{C}$ at $6^{\circ} \mathrm{C} / \mathrm{min}$ and was maintained at $250^{\circ} \mathrm{C}$ for $4 \mathrm{~min}$. Data were collected and treated with Galaxie software (Varian 2002).

\section{Gas chromatography-Mass spectrometry (GC-MS) analyses}

Identification of chemical compounds present in the tested extracts was made by GCMS. These analyses were carried out using a Varian 3400 gas chromatograph coupled to a Saturn II mass spectrometer with a SPI injector programmed at $250^{\circ} \mathrm{C}$. Two different columns were used. For CC paper extracts we used a VF5-MS (50 m long x $0.20 \mathrm{~mm}$ internal diameter x $0.33 \mu \mathrm{m}$ thick film) and the carrier gas Helium at 20 psi. For VC paper extracts we used a 
VF35MS (30 m long x $0.32 \mathrm{~mm}$ internal diameter x $0.5 \mu \mathrm{m}$ thick film) and the carrier gas at 10 psi. The two columns were heated following the same program: The initial temperature of the column was $50^{\circ} \mathrm{C}$ for $1 \mathrm{~min}$, and then the temperature was increased gradually up to $300^{\circ} \mathrm{C}$ at $8^{\circ} \mathrm{C} / \mathrm{min}$. Interpretation on mass-spectrum GC-MS was conducted using the database of National Institute Standard and Technology (NIST). The spectrum of the unknown components was compared with the spectrum of known components stored in the NIST library.

\section{Data analyses}

The distribution of binary choice tests as a function of the proportions of aggregated nymphs on one of the resting papers was calculated according to the method described by Deneubourg et al. (1987). A bimodal or U-shaped pattern of the frequency distribution of tests indicates that, in most tests, individuals aggregated all together and chose one or the other of the resting sites (classes 0-20\% and 81-100\%). Two similar branches of the U indicate that choices were random and that nymphs aggregated as often on either of the papers as expected in control tests. Different heights of the two branches of the $U$ indicate a significant choice, and that subjects aggregated more often on one of the papers. Bell-shaped curves indicate that in most tests individuals were not aggregated all together. They formed groups of different sizes on both papers.

$\mathrm{X}^{2}$ tests were used to compare distributions of tests. Times spent in the odorized arm and control arm of the Y-olfactometer tests were analysed using Wilcoxon matched-pairs test (Statistica, 2004).

\section{Results}

Selection of one of the filter paper as resting site in binary choice tests in Petri dishes, results both from perception of volatile molecules and from contact with heavier molecules present in the deposited blend. In Y-olfactometer tests, times spent in each arm depended on the attractive effect of the volatile blend perceived by the subjects. Both types of test are complementary and reveal information about chemical blends able to attract and to maintain the insects in a given area.

\section{Control tests}

Nymphs aggregated on either of the filter papers in binary choice tests. The distribution of tests in relation to the number of nymphs on one of the resting sites formed a ' $U$ ' shape 
curve when nymphs were given a choice between two control papers. This distribution indicated that nymphs choose equally either of the control papers $\left(X^{2}=0.028, p<0.05\right)$ (Fig. 1). This confirms that $P$. americana is a gregarious species.

Adult males exhibited no stress in the Y-olfactometer. They walked normally in the common stem, made a choice and then entered one of the arms. They went in and out of the arms several times. Males spent $48 \%$ of the test duration the common stem. Control tests, with two odourless air flows, revealed a small, but not significant, preference for the right arm (t-test, $\mathrm{t}=1.27, P>0.05)$ (Table 1$)$. To avoid this bias and to be sure an odour was attractive, all odours to be tested were presented in the left arm.

\section{CC papers}

\section{Binary choice tests}

Nymphs aggregated on the CC papers in $74 \%$ of the tests (Fig. 1). Nymphs aggregated preferentially on the conditioned site $\left(\mathrm{X}^{2}=34, P<0.001\right)$.

Nymphs aggregated on the papers conditioned with CC paper dichloromethane extracts in $42 \%$ of the tests $\left(X^{2}=1.88, P>0.05\right)$. Nymphs aggregated on the papers conditioned with CC paper methanol extracts in $44 \%$ of the tests $\left(\mathrm{X}^{2}=2.31, P>0.05\right)$. In neither of these two experiments, nymphs selected the conditioned site to aggregate.

When papers were conditioned with the mixture of both dichloromethane and methanol extracts, they induced aggregation in $58 \%$ of the tests. Nymphs selected significantly the site conditioned with the mixture of the two extracts $\left(\mathrm{X}^{2}=9.25, P<0.001\right)$.

\section{GC-MS analyses}

CHs accounted for $90.29 \%$ of the total amount of CC paper dichloromethane extracts. P. americana $\mathrm{CHs}$ have been identified previously (Saïd et al. 2005a). A few other molecules appeared in small peaks, each representing less than $1 \%$ of the total amount. As these molecules were present in higher quantities in the $\mathrm{CC}$ paper methanol extracts, they were identified in these extracts.

CC paper methanol extracts contained a larger number of molecules having different chemical functions. CHs present in the CC paper methanol extracts still represented $60 \%$ of the total amount. Most of the remaining compounds were fatty acids: $24 \%$ of the total amount. Hydrocarbons and ketones were also present, but in very small amounts (Fig. 2, 
Table. 1). As all these molecules have smaller molecular weights than $\mathrm{CHs}$, they are more volatile.

\section{Tests in a Y-olfactometer}

Males spent significantly more time in the arm odorized with CC papers than the control arm (t-test, $\mathrm{t}=4.35, P<0.001$ ) (Table. 2$)$. They also spent significantly more time in the arm odorized with methanol CC paper extracts ( $\mathrm{t}$-test, $\mathrm{t}=2.77, P<0.01)$. Therefore, $\mathrm{CC}$ paper methanol extracts contained attractive volatile molecules that were present on the $\mathrm{CC}$ papers.

When the arm was odorized with $\mathrm{CH}$ extracts of 20 first instar nymphs, males did not spend significantly more time in the odorized arm (t-test, $\mathrm{t}=0.43, P>0.05$ ).

Nevertheless, when a circular disc conditioned with the same concentration of $\mathrm{CHs}$ was added at the far end inside the arm odorized by CC paper methanol extracts, males spent significantly more time in the odorized arm than in the control arm (t-test, $\mathrm{t}=3.54, P<$ $0.001)$

Time spent in the arm odorized with CC paper methanol extracts increased significantly from $105 \mathrm{~s}$ to $145 \mathrm{~s}$ (Table 2 ) when $\mathrm{CH}$ extracts that could be touched were added $\left(\mathrm{X}^{2}=6.4\right.$, $P<0.05)$.

Both types of tests (binary choice tests with young nymphs and Y-olfactometer tests with adult males) led to similar conclusions. Test results were enhanced when cockroaches could perceive volatiles emitted by conspecifics and could have contacts with conspecific CHs. In binary choice tests CC papers provide both volatiles that can be extracted in methanol and $\mathrm{CHs}$ that had been deposited. In the Y-olfactometer, cockroaches could perceive both volatiles from the $\mathrm{CC}$ papers carried by the air-flow and have contact with $\mathrm{CH}$ extracts placed in the arm.

The selection of the conditioned paper or the increase of the time spent in the conditioned arm, both indicated that nymphs were attracted from a distance and then maintained on site by contact with CHs. Therefore, to identify the active part of the complex volatile blend extracted from CC papers, volatile molecules were selectively collected and their efficiency was tested.

\section{VC papers}

\section{Binary choice tests}


Papers conditioned by volatiles emitted by nymphs (VC papers) induced aggregation in $97 \%$ of the tests (Fig. 1). Nymphs selected significantly the conditioned site to aggregate $\left(\mathrm{X}^{2}\right.$ $=34, P<0.001)$.

Similarly, nymphs selected significantly the site conditioned with VC paper methanol extracts $(53 \%$ of the tests $)\left(\mathrm{X}^{2}=5.76, P<0.05\right)$.

\section{Tests in a Y-olfactometer}

Males spent significantly more time in the arm odorized with VC papers than in the control arm (t-test, $\mathrm{t}=2.68, P<0.01)($ Table 2$)$.

They also spent significantly more time in the arm odorized with methanol VC paper extracts (t-test, $\mathrm{t}=2.38, P<0.05$ ). These extracts contained volatile molecules present in the VC papers.

\section{GC-MS analysis}

Nine molecules were identified in the VC paper methanol extracts. They included 3,5bis(1,1dimethyl ethyl) phenol, penta-ethylene glycol, five saturated fatty acids: dodecanoic acid, tetradecanoic acid, pentadecanoic acid, hexadecanoic acid, octadecanoic acid and two unsaturated fatty acids: hexadecenoic acid and octadecenoic acid (Fig. 3, Table 3). Hexadecanoic acid was the major compound in the natural blend.

\section{Volatile synthetic chemical compounds}

Six synthetic fatty acids and of pentaethylene glycol, identified in the VC paper extracts, were tested individually in binary choice tests.

When papers were conditioned with dodecanoic acid $\left(\mathrm{X}^{2}=0, P>0.05\right)$ or octadecanoic acid $\left(\mathrm{X}^{2}=0.04, P>0.05\right)$, nymphs did not select significantly the conditioned sites to aggregate. When papers were conditioned with tetradecanoic acid $\left(\mathrm{X}^{2}=0.33, P>0.05\right)$ or hexadecenoic acid $\left(\mathrm{X}^{2}=2.27, P>0.05\right)$, not only the conditioned sites were not selected, but aggregation levels were low (Fig. 4).

When papers were conditioned with hexadecanoic acid $\left(\mathrm{X}^{2}=0.8, P>0.05\right)$ or penthaethylene glycol $\left(\mathrm{X}^{2}=2.57, P>0.05\right)$, nymphs selected the conditioned site more often than the control papers although no significant differences between the two sites could be evidenced. 
When papers were conditioned with pentadeanoic acid, nymphs selected preferentially the conditioned papers $\left(\mathrm{X}^{2}=7.14, P<0.01\right)$. Pentadeanoic acid was the only fatty acid able to induce significant choice of the conditioned site (Fig. 4).

Papers conditioned with a mixture of the three more attractive molecules (hexadecanoic acid, pentadecanoic acid and pentaethylene glycol), induced aggregation in $60 \%$ of the tests. Nymphs selected preferentially the conditioned site to aggregate $\left(\mathrm{X}^{2}=6, P<0.05\right)$ (Fig. 4).

\section{Discussion}

To identify the molecules involved in aggregation processes in the cockroach $P$. americana, two types of bioassays (binary choice tests and Y-olfactometer) were used. Binary choice tests in Petri dishes have been used previously in our laboratory to test aggregation abilities in cockroaches (Rivault and Cloarec 1998, Leoncini and Rivault 2005). The choice of one of the sites to aggregate indicated that the molecular blend present on that site was able to induce the choice and to maintain the aggregation of the cockroaches. The stimulus can act through the olfactory pathway as well the tactile pathway. Tests in the Y-olfactometer gave slightly different results. The increase in time spent in one of the odorized arms indicated that the chemical blend was able to attract cockroaches from a distance and that it acted only through the olfactory pathway. Results of both types of bioassays are complementary and helped us to evidence and to compare the role of different types of molecular blends.

As our previous results (Leoncini and Rivault 2005) demonstrated, aggregation is induced through chemical communication in P. americana. Papers conditioned by contact with conspecifics (CC papers) induced aggregation in binary choice tests. This result indicates that chemical factors deposited on the conditioned papers played a role in the choice of rest site and induced aggregation. Similar results were obtained with B. germanica under similar test conditions (Rivault and Cloarec 1998). These conspecific contact conditioned papers contain a complex blend of molecules that included cuticular hydrocarbons, faeces, and emitted volatiles. When the blend was separated by extractions in different solvents (dichloromethane and methanol) into two parts, neither of the parts was able to induce aggregation. Neither dichloromethane extracts nor methanol extracts induced aggregation in binary choice tests. Only the mixture of both types of extracts induced aggregation. The efficiency of $\mathrm{CC}$ paper dichloromethane extracts that contained small amounts of $\mathrm{CHs}$, 
increased when methanol extracts were added. This means that at least some of the molecules that are present in each type of extracts are required to induce aggregation and that they act simultaneously, in complement or in synergy. We know that, when presented alone, CHs can induce aggregation only at very high concentrations. The amounts of $\mathrm{CHs}$ necessary to induce aggregation in these experiments were far beyond a "natural stimulating" situation although some factors, like incomplete extraction or presence of solvent residues could reduce the efficiency of the tested blend (Saïd et al. 2005b). The presence of many molecules with molecular weights lower than those of the $\mathrm{CHs}$ in the methanol $\mathrm{CC}$ paper extracts led us to assume that molecules more volatile than $\mathrm{CHs}$ are involved in the aggregation processes.

$\mathrm{Y}$-olfactometer tests confirmed this hypothesis. Males were attracted to arms odorized with CC papers or CC paper methanol extracts. This demonstrated that molecules perceived through the olfactory pathway were involved in aggregation processes. Furthermore, the efficiency of volatiles from CC paper methanol extracts was significantly improved when their action was combined with contact with low doses of CHs. This result indicated that very low doses of $\mathrm{CHs}$ are sufficient and necessary to maintain cockroaches in the odorized arm once they have been attracted there. Therefore, some of the molecules present in the methanol CC paper extracts seem to be attractive from a distance while cuticular hydrocarbons play the role of an arrestant, acting through contact, although the three most important cuticular hydrocarbons of the species profile could be collected in the volatile blend at very short distance and perceived by olfactory neurons (Saïd et al. 2005b). Their olfactory perception does not imply that they are detected as an aggregation signal and our present results indicate that this does not seem to be case. $\mathrm{CH}$ extracts of Schistocerca gregaria $(\mathbf{F}$.) induce the transition from the solitarious to the gregarious phase in second and fifth instar larvae when perceived by contact (Heifetz et al. 1997). CHs of many moths (Geometridae, Arctiida and Noctuidae) attract conspecifics over long distances and alkenes are found in volatile sex pheromones (Howard and Blomquist 2005).

Furthermore, filter papers conditioned by volatile compounds emitted by live cockroaches (VC papers) and methanol extracts of VC papers induced aggregation in binary choice tests and increased the time spent in the odorized arm of the Y-olfactometer.

For the first time long-chained fatty acids have been identified here in the volatile emissions of $P$. americana. Only 10 molecules were identified from VC paper methanol extracts: 3,5-bis(1,1dimethyl ethyl) phenol, penthaethylene glycol and seven fatty acids. No $\mathrm{CHs}$ were found in the VC paper methanol extracts. Although the VC paper methanol extracts contained no $\mathrm{CHs}$, they induced aggregation on the conditioned site in binary choice tests. We 
assumed that the chemical blend attracted the cockroaches to the site. Then they were maintained on the site by increased contacts between individuals that favoured close range chemical interactions via $\mathrm{CHs}$ carried by the nymphs.

The methanol extracts of CC papers and VC papers have saturated and unsaturated fatty acids in common and both types of papers induced aggregation in our experimental tests. The VC papers had less molecules than the CC paper methanol extracts. This can be easily explained by the fact that faeces were also present on the CC papers that were conditioned for several days. Although faeces are attractive in some cockroach species (Miller et al. 2000), their absence in the VC paper chemical blend did not impair aggregation. It seems likely that are not part of the aggregation message. According to (Brossut 1975), all attractive substances are not necessarily pheromones. Ethyl phenols were identified by (Brossut 1983) as allomones. They are secreted by sternal glands in P. americana and have a repellent effect. When tested individually, none of the compounds present in VC papers except pentadecanoic acid induced aggregation in binary choice tests. A mixture of two fatty acids (hexadecanoic acid, pentadecanoic acid) plus pentaethylene glycol induced the highest aggregation level observed in binary choice tests. The attractive effects of fatty acids for Periplaneta americana still remains controversial. Many fatty acids extracted from faeces were either repellent or ineffective (McFarlane and Alli 1986). Lactic acids and C2-C6 fatty acids were repellent at high concentrations and ineffective at low concentrations, whereas butyric acid presented in low concentrated aqueous solutions was attractive to $P$. americana nymphs (McFarlane and Alli 1986).

The identification of the molecules involved in aggregation processes in $P$. americana will not be complete until the secretion source of the volatile molecules (in particular hexadecanoic acid, pentadecanoic acid and pentaethylene glycol) collected via the VC papers remains unknown. These attractive volatile molecules cannot be given the status of pheromone signals until their origin is elucidated. The glandular system of P. americana is complex but does not include mandibular glands (Brossut and Sreng 1985), which is the secretion source of the aggregation pheromone of some Blaberidae species (Brossut 1979, Brossut et al. 1974)

To conclude, our results evidenced that aggregation processes in Periplaneta americana relies on a dual mechanism: attraction over long distances by three volatile molecules (hexadecanoic acid, pentadecanoic acid, pentaethylene glycol) that could be the pheromonal signal and maintenance on site by CHs. Cuticular hydrocarbons are considered as specific recognition signals in many social insects (Howard and Blomquist 2005) and could play a 
similar role in cockroach aggregation processes by decreasing the interindividual tolerance threshold. Insect pheromones are frequently multicomponent blends that can in certain systems function synergistically (Tillman et al. 1999).

\section{Acknowledgements}

This work received financial support from the European Commission (IST Program: 2001-35506: LEURRE). I.S. was supported by a post-doctoral grant from the LEURRE program. 


\section{References}

Ali, M. F., and Morgan E. D. 1990. Chemical communication in insect communities: a guide to insect pheromones with special emphasis on social insects. Biol. Rev. Cambridge Philos. Soc. 65: 227-247.

Applebaum, S. W., and Heifetz Y. 1999. Density-dependent physiological phase in insects. Annu. Rev. Entomol. 44:317-341.

Bell, W. J., and Adiyodi K. G. 1982. The American Cockroach. London: Chapman \& Hall Ltd.

Borden, J. H. 1974. Aggregation pheromones in the Scolytidae. In: Pheromones (ed. M. C. Birch), pp. 135-160. Amsterdam: North-Holland.

Brossut, R. 1975. Pheromonal bases of gregarism and interattraction. In: Pheromones and defensive secretions in social insects, (ed. Noirot C.), pp. 67-85: Symposium IUSSI.

Brossut, R. 1979. Gregarism in cockroaches and in Eublaberus in particular. In: Chemical ecology: odour communication in animals. (ed. Ritter. F.J.), pp. 237-246. Amsterdam: Elsevier.

Brossut, R. 1983. Allomonal secretions in cockroaches. J. Chem. Ecol. 9: 143-158.

Brossut, R., Dubois P., Rigaud, J. 1974. Le grégarisme chez Blaberus craniifer: isolement et identification de la phéromone. J. Insect Physiol. 20: 529-543.

Brossut, R., Sreng, L. 1985. L'univers chimique des blattes. Bulletin de la Société Entomologique de France 90: 1266-1280.

Byers, J. A. 1989. Chemical ecology of bark beetles. Experientia. 45: 271-283.

Cornwell, P. B. 1968. The cockroach. vol 1: A Laboratory Insect and an Industrial Pest. London: Hutchinson \& CO.

Deneubourg, J. L., Goss, S., Pasteels, J. M., Fresneau, D., and Lachaud, J. P. 1987. Selforganization mechanisms in ant societies (II): Learning in a foraging and division of labor. In: From individual to collective behavior in social insects., eds. J. M. Pasteels and J. L. Deneubourg, pp. 177-196. Basel, Birkhaüser Verlag.

Deneubourg, J. L., Gregoire, J. C., and Le Fort, E. (1990). Kinetics of larval gregarious behavior in the bark beetle Dentroctonus micans (Coleoptera: Scolytidae). J. Insect Behav. 3: 169-182.

Grassé, P. P. 1952. Le fait social: ses critères biologiques, ses limites. In: Structure et physiologie des sociétées animales, (ed. Grassé. P.P.), pp. 7-17. Paris: CNRS. 
Heifetz, Y., Boekhoff, I., Breer, H., and Applebaum, S. W. 1997. Cuticular hydrocarbons control behavioural phase transition in Schistocerca gregaria larvea and elicit biochemical responses in antennae. Insect Biochem. Mol. Biol. 27: 563-568.

Howard, R. W., and Blomquist, G. J. 2005. Ecological, behavioral, and biochemical aspects of insect hydrocarbons. Annu. Rev. Entomol. 50: 371-393.

Ishii, S., and Kuwahara, Y. 1967. An aggregation pheromone of the german cockroach Blattella germanica (Orthoptera: Blattellidae).1- Site of the pheromone production. Appl. Entomol. Zool. 2: 203-217.

Krause, J., and Ruxton, G. 2002. Living in groups. Oxford, USA: Oxford University Press.

Leoncini, I., and Rivault, C. 2005. Could species segregation be a consequence of aggregation processes? Example of Periplaneta americana (L.) and P. fuliginosa (Serville). Ethol. 111: 527-540.

McFarlane, J. E., and Alli, I. 1986. Aggregation of larvae of Blattella germanica by lacticacid present in excreta. J. Chem. Ecol. 12: 1369-1376.

Miller, D. M., Koehler, P. G., and Nation, J. L. 2000. Use of fecal extract trails to enhance trap catch in German cockroach (Dictyoptera: Blattellidae) monitoring stations. J. Econ. Entomol. 93: 865-870.

Parrish, J. K., and Hamner, W. M. 1997. Animal groups in three dimensions. Cambridge: Cambridge University Press.

Ritter, F. J., and Persoons, C. J. 1975. Recent development in insect pheromone research in particular in the Netherlands. Netherlands. J. Zool. 25: 261-275.

Rivault, C., and Cloarec, A. 1998. Cockroach aggregation: discrimination between strain odours in Blattella germanica. Anim. Behav. 55: 177-184.

Rivault, C., Cloarec, A., and Sreng, L. 2002. Are differences in hydrocarbon profiles able to mediate strain recognition in German cockroaches (Dictyoptera: Blattellidae)? Eur. J. Entomol. 99, 437-444.

Rivault, C., and Durier, V. 2004. Homing in German cockroaches, Blattella germanica (L.) (Insecta:Dictyoptera): Multi-channnelled orientation cues. Ethol. 110: 761-777.

Roth, L., Willis, and E. R. 1960. The biotic associations of cockroaches. Smithsonian Miscellaneous Collections. 141: 1-470.

Saïd, I., Costagliola, G., Leoncini, I., and Rivault, C. 2005a. Cuticular hydrocarbon profiles and aggregation in four Periplaneta species (Insecta: Dictyoptera). J. Insect Physiol. 51: 9951003. 
Saïd, I., Gaertner, C., Renou, M., and Rivault, C. 2005b. Perception of cuticular hydrocarbons by the olfactory organs in Periplaneta americana (L.) (Insecta: Dictyoptera). J. Insect Physiol. 51: 1384-1389.

Sakuma, M., Fukami, and H. 1990. The aggregation pheromone of the German cockroach, Blattella germanica (L.) (Dictyoptera: Blattellidae): Isolation and identification of the attractant components of the pheromone. Appl. Entomol. Zool. 25: 355-368.

Sakuma, M., and Fukami, H. 1993. Aggregation arrestant pheromone of the german cockroach Blattella germanica (L.) (Dictyoptera: Blattellidae): isolation and structure elucidation of blattellastanoside-A and-B. J. Chem. Ecol. 19: 2521-2541.

Tillman, J. A., Seybold, S. J., Jurenka, R. A., and Blomquist, G. J. 1999. Insect pheromones. An overview of biosynthesis and endocrine regulation. Insect Biochem. Mol. Biol. 29: 481514.

Tirard, A., Renucci, M., Provost, E., Khlat, J., and Clement, J. L. 2002. Are polyamines involved in olfaction? An EAG and Biochemical study in Periplaneta americana antennae. Chem. Senses. 27: 417-423.

Wertheim, B., Van Baalen, E.-J. A., Dicke, M., and Vet, L. E. M. 2005. Pheromone-mediated aggregation in nonsocial arthropods: an evolutionary ecological perspective. Annu. Rev. Entomol. 50: 321-346.

Wyatt, T. D. 2003. Pheromones and animal behaviour: Communication by smell and taste. Cambridge: Cambridge University Press. 
Figure 1
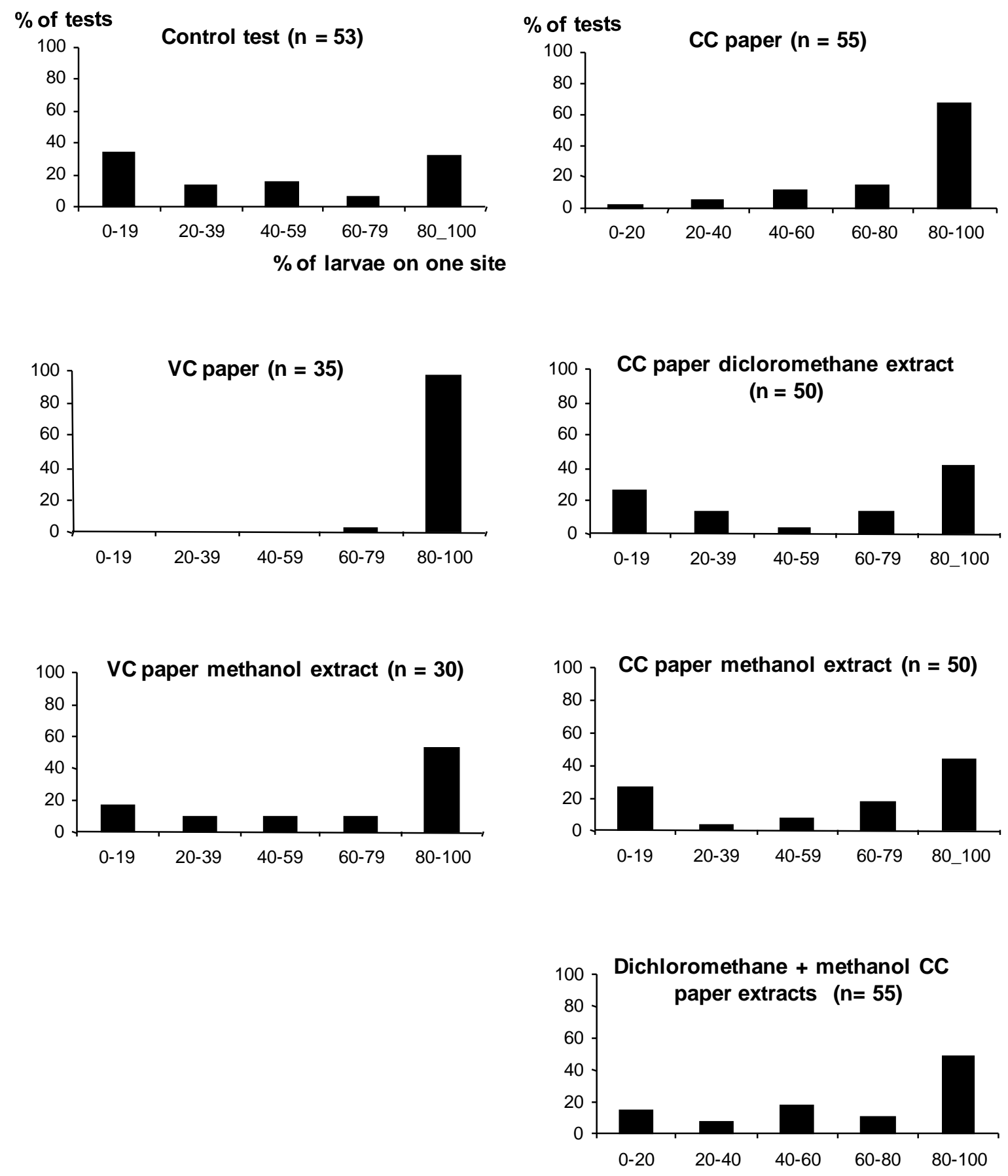
Figure 2

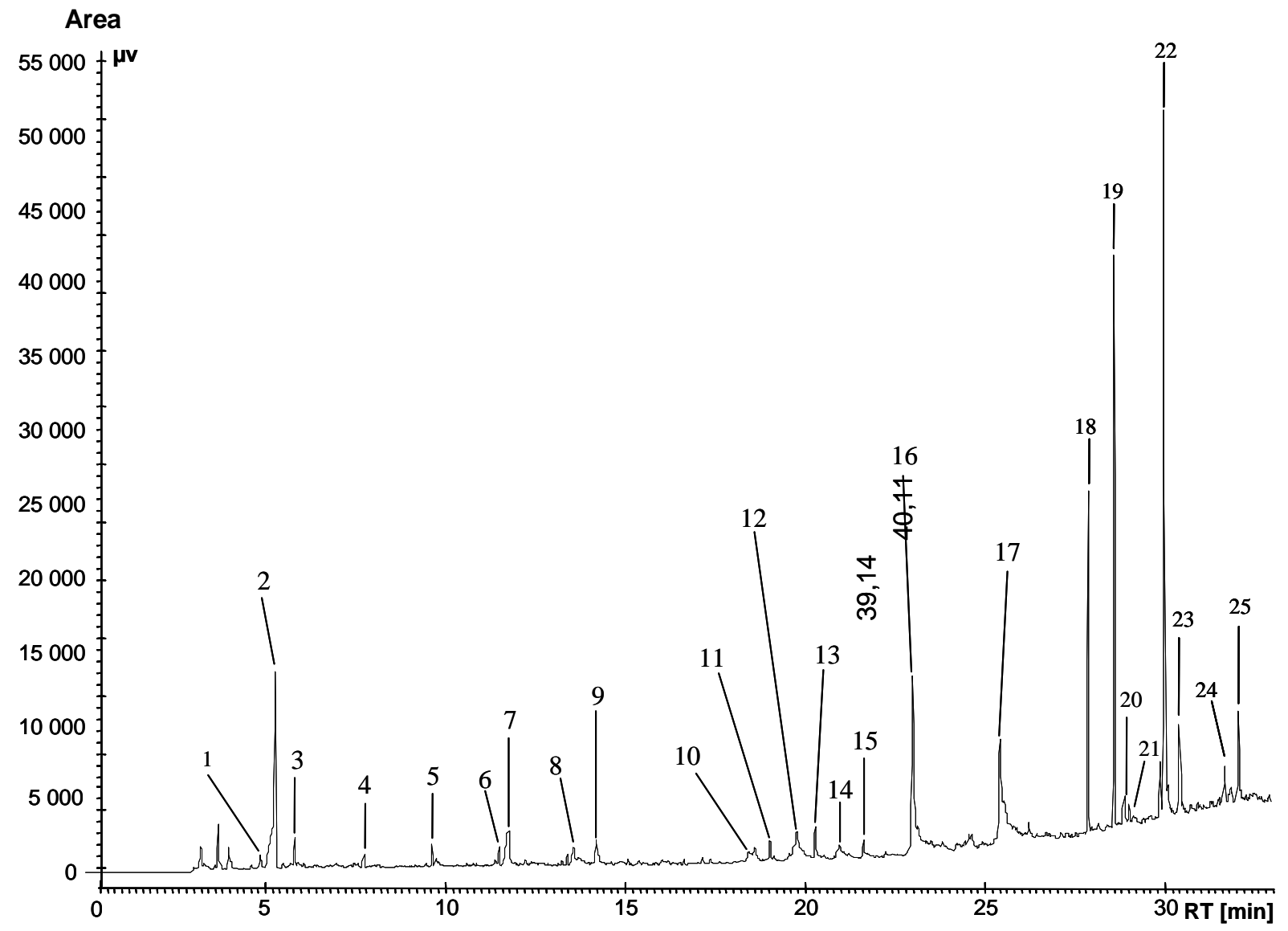


Figure 3

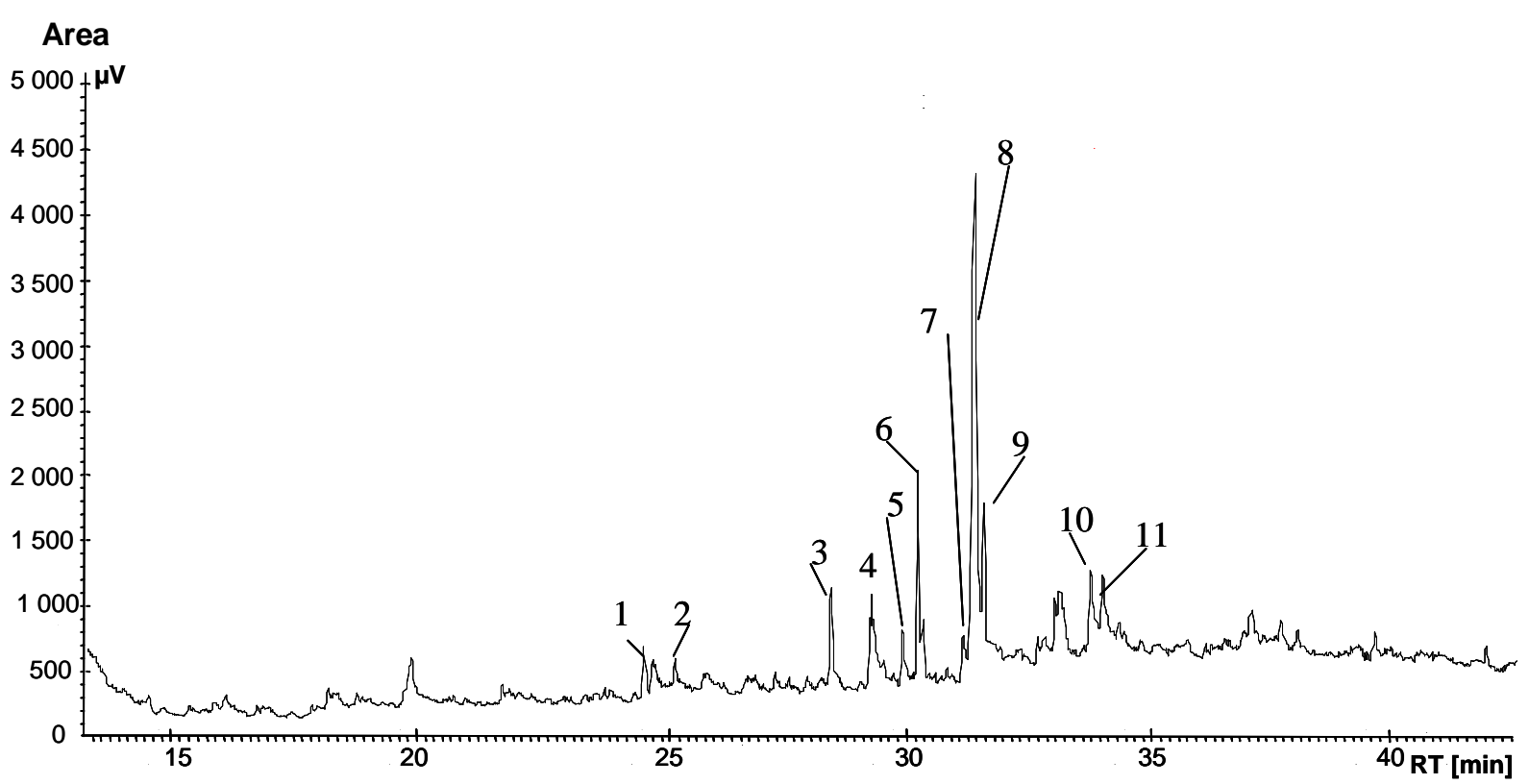




\section{Figure 4}
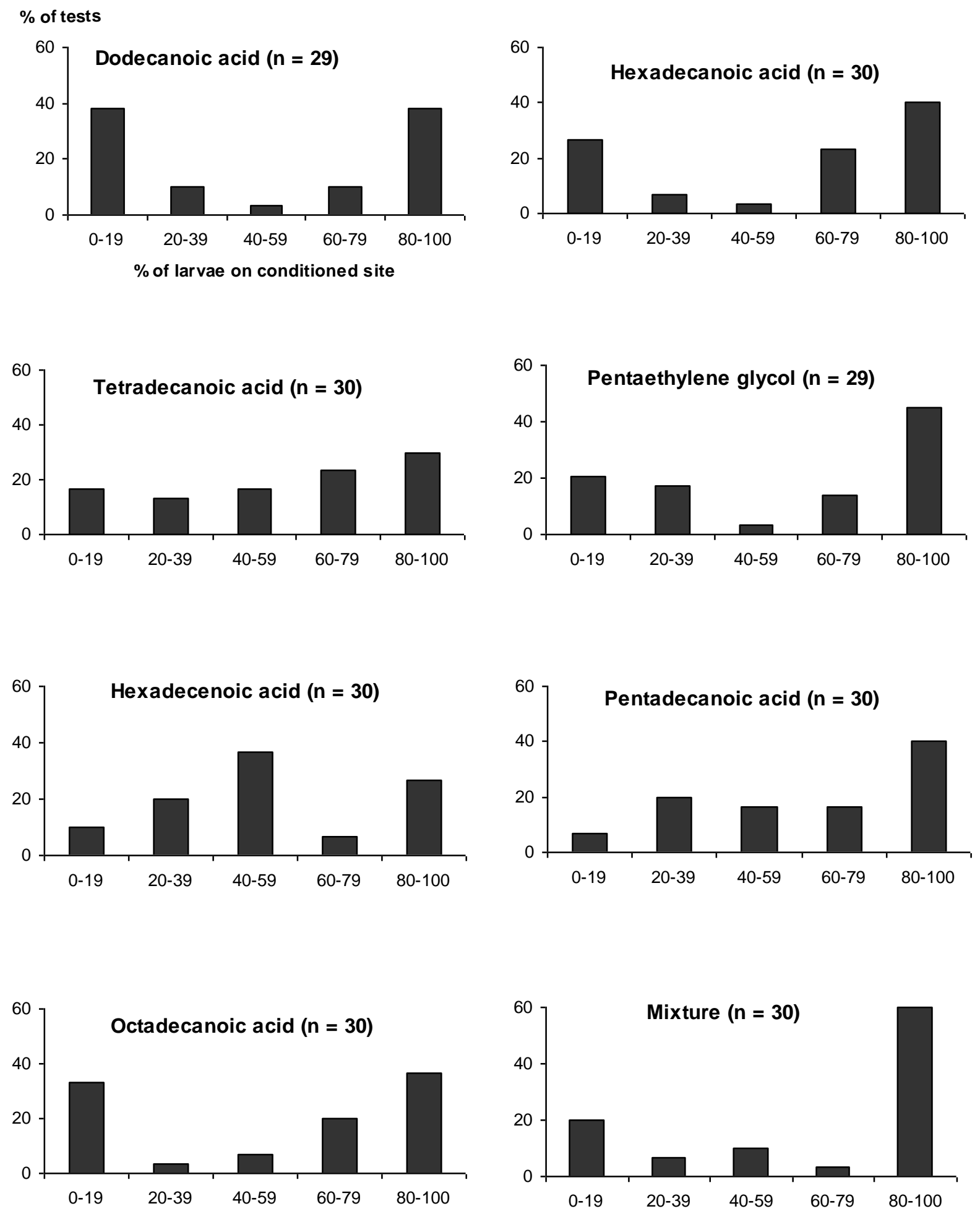


\section{Figure legends}

\section{Fig. 1.}

Binary choice tests in Petri dishes. Distribution of tests (\% of the total number of tests) as a function of the proportions of nymphs aggregated on one of the sites (usually the conditioned site). Proportions of nymphs resting on the conditioned site were divided into five classes. All tests were made with groups of 10 nymphs. $n=$ number of tests in each experiment.

In control tests, both sites were control papers. In all the other experiments, the represented site was the conditioned site: VC paper, VC paper methanol extracts, CC paper, CC paper dichloromethane extracts, CC paper methanol extracts or a mixture of both types of CC paper extracts.

\section{Fig. 2.}

Profile of chemical compounds obtained in methanol extracts of filter papers conditioned during three days by 20 first instar nymphs of Periplaneta americana by contact (CC papers). Numbers correspond to names of compounds in table 1. Legend: RT = retention time $(\mathrm{min})$; $\mu \mathrm{V}=$ microvolts.

\section{Fig. 3.}

Profile of chemical compounds obtained in methanol extracts of filter papers conditioned by volatile odours emitted by 10 last instar nymphs of Periplaneta americana replaced every three hours for two successive 12-h photophases (VC papers). Numbers correspond to names of compounds in table 3. Legend: RT = retention time (min);

\section{Fig. 4.}

Binary choice tests in Petri dishes. Distribution of tests as a function of the proportion of nymphs aggregated on the conditioned site. Proportions of nymphs aggregated on one of the papers were divided into five classes. All tests were made with groups of 10 nymphs. $n=$ number of tests in each experiment. The conditioned site received $10 \mu \mathrm{l}$ of synthetic solution of one of the six fatty acids or pentaethylene glycol at $1 \mu \mathrm{g} / \mu \mathrm{l}$. A mixture of hexadecanoic acid (70\%), pentadecanoic acid (20\%) plus pentaethylene glycol (10\%) was tested at $100 \mu \mathrm{g} / \mu \mathrm{l}$. 
Table 1. Chemical compounds identified in the CC paper methanol extracts.

Legend: $\mathrm{N}=$ number indicated in Fig.2; RT: retention time (min); Area (\%): relative amounts of compounds.

\begin{tabular}{|c|c|c|c|}
\hline Name & $\mathbf{N}$ & RT & Area $(\%)$ \\
\hline Clhorobenzene $(50,51,77,91,106,112,114)$ & 1 & 4,98 & 3,8 \\
\hline 2-pentanone 4-OH 4-methyl $(43,58,59,83,98,101)$ & 2 & 5,34 & 8,8 \\
\hline Hydrocarbon $(43,57,71,85)$, & 3 & 5,89 & 0,6 \\
\hline Hydrocarbon $(43,57,71,85)$, & 4 & 7,83 & 0,3 \\
\hline Hydrocarbon $(43,57,71,85)$, & 5 & 9,76 & 0,4 \\
\hline Hydrocarbon $(43,57,71,85)$, & 6 & 11,65 & 0,3 \\
\hline Benzoic acid $(45,51,77,94,105,122)$ & 7 & 11,94 & 1,9 \\
\hline Propane dioic acid phenyl $(43,45,65,91,136)$ & 8 & 13,76 & 0,7 \\
\hline Salycilic acid $(45,53,63,92,120,138)$ & 9 & 14,38 & 1,1 \\
\hline Benzoic acid 4-OH $(45,53,65,93,121,138)$ & 10 & 18,74 & 0,7 \\
\hline $2 \mathrm{H}$ indol 2-one 1,3-dihydro $(51,63,78,104,133)$ & 11 & 19,29 & 0,5 \\
\hline Benzene acetic acid 3-OH $(45,51,63,77,107,123,152)$ & 12 & 20,5 & 2,1 \\
\hline Tetradecanoic acid $(41,55,60,69,73,83,87,97,101,115,129,137,143,157,171,185,199,228)$ & 13 & 20,59 & 0,9 \\
\hline Izene propanoic acid 4-OH $(45,55,65,77,91,107,120,121,149,166)$ & 14 & 21,23 & 0,7 \\
\hline Pentadecanoic acid $(41,55,60,69,73,83,87,97,101,115,129,137,143,157,171,185,199,242)$ & 15 & 21,98 & 0,6 \\
\hline Hexadecanoic acid $(41,55,60,69,73,83,87,97,101,115,129,137,143,157,171,185,199,213,239,256)$ & 16 & 23,34 & 8,5 \\
\hline Octadecanoic acid $(41,55,60,69,73,83,87,97,101,115,129,137,143,157,171,185,199,241,264,284)$ & 17 & 25,83 & 7,3 \\
\hline n-Pentacosane & 18 & 28,28 & 6,3 \\
\hline 3-Methylpentacosane & 19 & 29,02 & 11,0 \\
\hline n-Hexacosane & 20 & 29,3 & 0,6 \\
\hline Dimethylpentacosane & 21 & 29,43 & 0,3 \\
\hline 6,9-Heptacosadiene & 22 & 30,46 & 37,9 \\
\hline n-Heptacosane & 23 & 30,91 & 1,8 \\
\hline n-Octacosane & 24 & 32,18 & 0,7 \\
\hline n-Nonacosane & 25 & 32,56 & 2,3 \\
\hline
\end{tabular}


Table 2. Y-olfactometer tests with Periplaneta americana males. Time (mean $\pm \mathrm{SE}$ in s) spent in the common stem and in each arm by males tested individually during $5 \mathrm{~min}$. Left arm is always the odorized arm.

\begin{tabular}{lllll}
\hline & $N$ & Left arm & Right arm & Common stem \\
\hline Control test & 25 & $68.16 \pm 6.18$ & $86.28 \pm 10.33$ & $145 \pm 9.92$ \\
CC papers & 30 & $127 \pm 12.45^{* *}$ & $54 \pm 6.44$ & $118.24 \pm 14.86$ \\
CC paper methanol extracts & 19 & $105 \pm 18.6^{* *}$ & $54 \pm 5.85$ & $140.82 \pm 5.85$ \\
CHs (extracts of 20 nymphs/paper) & 34 & $83 \pm 10.02$ & $80 \pm 6.45$ & $136.20 \pm 11.57$ \\
CC paper methanol extracts $+\mathrm{CH}$ & 19 & $145 \pm 17.23^{* *}$ & $41 \pm 7.12$ & $112.63 \pm 7.12$ \\
dichloromethane extracts presented & & & & \\
in contact & & & & \\
VC paper & 22 & $84 \pm 8.45^{* *}$ & $50 \pm 7.41$ & $164.72 \pm 7.41$ \\
VC paper methanol extracts & 21 & $85 \pm 12.90^{* *}$ & $57 \pm 9.52$ & $157.23 \pm 14.59$ \\
\hline
\end{tabular}

Significant differences from control arm: **: $P<0.005$ (Wilcoxon matched-pairs test between the left and the right arm). $\mathrm{N}=$ number of tests. 
Table 3: Chemical compounds identified in VC paper methanol extracts.

Legend: $\mathrm{N}=$ number indicated in Fig.3; RT: retention time (min); Area (\%): relative amounts of compounds.

\section{Name}

Phenol 3,5-bis(1,1dimethyl ethyl) $(41,57,65,77,91,107,123,135,151,163,175,191,206)$

Dodecanoic acid $(41,55,60,69,73,83,87,97,101,115,129,137,143,157,171,185,200)$

Tetradecanoic acid $(41,55,60,69,73,83,87,97,101,115,129,137,143,157,171,185,199,228)$

Penta ethylen glycol $(45,59,73,87,89,103,133)$

Pentadecanoic acid $(41,55,60,69,73,83,87,97,101,115,129,137,143,157,171,185,199,242)$

Phthalate $(41,57,76,104,121,149,205,223)$

Hexadecenoic acid $(41,55,60,67,69,73,81,96,110,123,148,179,236)$

Hexadecanoic acid $(41,55,60,69,73,83,87,97,101,115,129,137,143,157,171,185,199,213,239,256)$

Phthalate $(41,57,76,104,121,149,205,223)$

Octadecenoic acid $(41,55,60,67,73,81,96,110,123,135,166,264)$

Octadecanoic acid $(41,55,60,69,73,83,87,97,101,115,129,137,143,157,171,185,199,241,264,284)$
N RT

$1 \quad 24,68$

$2 \quad 25,33$

$3 \quad 28,56$

$4 \quad 29,38$

$5 \quad 30,04$

630,36

$7 \quad 31,28$

831,53

$9 \quad 31,71$

$10 \quad 33,94$

$11 \quad 34,18$
Area (\%)

2,80

1,64

7,89

8,30

3,81

9,26

2,83

42,11

7,17

6,94

5,88 